\title{
Analysis on the Current Situations of Excessive Goods Packaging and Its Protection
}

\author{
Yanling Tang a, Xijia Zhang \\ School of Foreign Languages, Changchun Institute of Technology, Jilin 130012, China \\ atangyanling_bird@yahoo.com
}

Keywords: packaging; environmental pollution; resources; consumption.

\begin{abstract}
With China's economic development, its domestic enterprises are attaching more importance to goods packaging. Packaging is playing an important role as an essential part of the circulation of commodities. But in recent years, excessive packaging has aroused extensive attention in the field of commodity circulation. Social development and the change of consumption ideas make excessive packaging contrary to China's development of circular economy. It is not only a waste of resources and energy, and pollution of the environment, but also misleads customers and harms the interests of customers. How to deal with the excessive packaging problem and promote reasonable-packaging has become one of the important problems in our country. The purpose of this paper is to present an analysis of the current situation, causes and hazards excessive packaging causes. A common ways to solve excessive packaging is to learn from foreign successful experiences, combine with our national conditions by improving the legal system, carrying out industry self-regulation, and promoting rational consumption.
\end{abstract}

\section{Introduction}

With the rapid development of the economy, people's living standard and demand for commodities also increase and the requirements for packaging are increasingly high as well. Whether or not being able to arouse consumer's purchasing desire is one of the most important standards to estimate how successful the commodity packaging design is. However, excessive packaging not only causes more production pollution but also damages the environment balance seriously. Therefore, it has attracted many countries' great attention.

Based on a related research, the paper analysis on current situation of excessive packaging in the economic market, and then offers solutions to problems caused by the excessive packaging.

\section{Analysis of Commodities in Excessive Packaging}

In recent years, when festival season approaches, the goods with excessive packaging are always focused by medium. Excessive packaging in our country is become more and more serious. A large number of needs beyond the basic functions of packaging appear, all kinds of gift boxes are placed in the most prominent shopping shelves, and many ordinary simple goods are also put in luxury clothes [1]. The goods over-packaged produce many problems and also causes much social harm. To make some effective regulations on goods excessive packaging has become a top priority. But with the start of this topic in depth, on the excessive packaging condemning is not limited to moon cake, health care products and other gifts, and also including many daily consumer goods. They had also been branded an "over- packaging" mark. It seems that our lives are being surrounded by excessive packaging. But what time does the situation come to an end? What kind of packaging is "appropriate"? How should we deal with the excessive packaging problem? All the questions concerned require solutions in urgent need.

The performance of goods excessive packaging, from the volume point of view, packing too large with too much materials uses and decorates luxury; from the essential points of view, the function of packaging twists and has suspected fraud, such as protection, communication, convenient and decorative functional excess. We subdivide the performance into the following points: 
1) Packing layer is too much. According to data showed in a tea market, the random survey found that a number of shops selling packaged tea have three or more layers [2]. From the inside to the outside, package includes bags, wooden box, foam box bottom, and sealed cans.

2) Packing gap is too large. The purpose of packaging is to protect products inside. The actual sale of goods packaging is far beyond the need of protection and its packaging gap is too large. For example, the aweto sales in the pharmacies, 20 stalks in all, however, each of them is similar as the length of two matches; the packaging box is full just like a 16-inch book. The inside of the packaging is filling with the cotton, foam, cardboard. The packaging materials take up the most of the position, causing the illusion of abundant goods. But actually the aweto just takes up a little space. Normally when we visit the doctor to get medication, the simple box packaging with the different size of drugs, only contains a few pieces of medicines. But it has a big container which is several times bigger than the drug packaging.

3) Packaging costs high. According to the materials survey, the price difference between common packaging of goods and exquisite gift packaging is usually one or two times. It is found that even in some supermarket, cosmetics imported from abroad has no beautiful gift packaging In order to meet certain domestic customers' need, the sellers equip the products with a special gift box and each packaging costs around RMB50 yuan or more.

4) Design and decoration is luxurious. The packaging materials often use brocade boxes, sandalwood boxes, gold boxes and etc. How attractive the packaging is and how exaggeration the packaging design use today have become the first problem the enterprise to solve. The designer may select any materials they can find and use. Sometimes the packaging materials seem much better than the products itself. There is no doubt that the function of product packaging is to attract consumers' attention, but to have proper packaging is essential for both consumers and the products.

Modern women are indeed an extremely powerful and appealing sector of consumers. It is time for business people to recognize that women consumers are a powerful force that cannot be overlooked. If businesses are interested in growing to new height of success, he or she should get a strategy to make sure "you have got women". Big international corporations which operate business on a global scale have begun to realize that women's economic power is no doubt going to affect their large share in market and spend more efforts on the research of women consumers' psychology and behavior, in order to make the product perfect "fit for her". However, it is not easy to gain women's satisfaction and preference if the marketers still hold their old stereotypical type about women only as housewife and do not have the subject-by-subject overview of women's attitude, behavior, consumer preference and so forth. Many companies still consider women as "minority" or niche consumers. Such "minority think" can cripple any significant change toward women consumers because it does not place women in their rightful place as majority consumers whose wants and needs are critical to marketing strategy.

\section{Preventive Measures for Commodity Excessive Packaging.}

Nowadays, the whole world ecological environment has become a common theme around us. Fundamentally speaking, the environment problem is due to human failure to handle the relationship between human activity and nature ecosystems during the process of economic and technology development. The new way of human civilization is "ecological civilization". It requires people reconstruction of human harmony and unity between human beings and nature. Every form of life is unique. No matter what value it has, it should obtain human respect. Human behavior or its consequences can change the nature and use up the natural resources. Therefore, human beings must fully recognize the serious consequences urgently and protect its stability and constant quality of the nature. Excessive packaging has become an important factor to destruct ecological balance and environmental pollution [3]. Focus on this phenomenon occurring and developing, national governments, society and individuals have the responsibility and obligation to prevent this phenomenon from recurring. 


\subsection{Aspects of Government}

The actual national conditions for Chinese laws and regulations are still imperfect, the consumer purchase power is continuously improved and the competition in the market is increasingly fierce. China should take lessons from the successful experience of foreign countries and take measures from the national, industry, consumers and other aspects. We not only strengthen the laws and regulations and form the industry self-regulations, but also create a simplicity consumer atmosphere.

1) Improvement of the Legal System. Laws and regulations are powerful methods to regulate all kinds of market behaviors. 2) Utilization of Foreign Experiences. China should study foreign experience and be ready to develop "packaging law" as soon as possible. Foreign packaging industry was invested earlier than China's. Many developed countries were already one step ahead to our nation in terms of legal system of packaging. They have enacted restrictions on goods excessive packaging laws and regulations, and have established a set of restrictions on the maturity over the practice of goods excessive packaging.

\subsection{Aspects of Society}

Facing this phenomenon, the industry self-regulation and social supervision is necessary. 1) Implementation of Industry Self-Regulation. Packaging industry should be based on the principles of scientific development and try to formulate a standard of packaging, and then strengthen industry self-regulation. 2) Enhancement of Social Supervision. However for all kinds of excessive packaging imagination, in addition to encouraging and supporting the enterprise advanced packaging trades and packaging product innovation, we also require a strengthening social supervision, and carrying out corporate responsibility.

\subsection{Aspects of Individuals}

After the national government and social supervision fulfilled, it also needs social individuals' consciousness [4]. Our society is made of people, each one can restrain oneself, and the phenomenon of excessive packaging must be taken a turn for the better. From the beginning of packaging design to the rational consumption, let us give a good packaging consumption environment to our economic market.

1) To solve the problem of excessive packaging, we needs take it roots. Packaging design is the beginning of package production. We should firstly make designers to know how harmful the excessive packaging is making them understand Chinese serious resource environment nowadays and also force them to be aware of the enormous risks of excessive packaging.

With economic development and social progress, people's demand for commodities packaging will be higher than before, requiring both affordable and beautiful appearance, safe and convenient but also recycled. It will become the development direction of products packaging. All units should release their minds to overcome the traditional ideas and then focus on technological innovation. On the way to managing goods excessive packaging, changing product structure, improving product quality and promoting packaging industry will be good for building a resource-saving and environment-friendly society.

It requires the combination of packaging designers and manufacturers need. The first is to enhance design innovation, in-depth market research with the principles of humanity according to market requirements, and then design a reasonable structure and goods style by using reasonable materials. The second is to strengthen material innovation, making sure that the package function has full use of renewable resources. As we known, China is the largest country with scarcity of resources most. Reduce toxic or harmful materials and the materials which affect the ecology of the environment and renewable natural resources use. The third is to strengthen the manufacturing technique innovation, using new technologies and new equipment to enhance the utilization ratio of materials and the quality of product packaging. At the same time we research and develop recycle packaging containers, which will extend packaging product life cycle. Guide designers to have rational design of resource-saving and environment-friendly products. We resolutely oppose excessive packaging enterprises and individuals.

2) Rational Consumption. 
Excessive packaging is a bad social morality produced by consumer's irrational consumption. If the society-atmosphere does not change, even with the government's related laws as constraints, it is certain that goods excessive packaging is difficult to cure. Therefore, to solve the problem of goods excessive packaging not only needs to change consumer consumption ideas, but also the fundamental transformation of social morality. Chinese consumers should enhance green consumerism, consciously resist the goods excessive packaging, and enhance self-protection awareness, environmental awareness and social responsibility. Consumers should pay more attention to the goods itself instead of the outside packaging. The government and consumer's association play their roles well. They provide timely information which shows serious data of resources and environment statistics to alarm consumers. By this way, goods excessive packaging will find no place to live.

All in all, to solve the problem of goods excessive packaging, it needs combine with the government, the society and individuals power. If we were short of each hand, this problem will not be solved actually.

\section{Summary}

Goods excessive packaging has become an ignored social problem, which results in wasting of our resources, polluting our environment, hindering the development of enterprises, even breeding corruption. Therefore, concerning its hazards, we need take measures through national laws and regulations specification, industry self-regulations, media and social supervision and guidance for rational consumer consumption. From these ways, the pernicious effects of excessive packaging to the whole society must be corrected gradually. Only if the communities have a clear understanding to excessive packaging and using the law to regulate with the joint efforts of consumers and the community, the problem must be effectively curbed. Shanghai CPPCC member Tang Enyu said, "Packaging itself is not wrong, what counts is that excessive packaging consume too many resources and waste causes environmental pollution. To control excessive packaging needs combine the economic levers, social supervision, consumer education and relevance standard establishment, and use the 'combination punches'."

In all of the fact that research level and the knowledge are limited, the findings also have many limitations. I hoped that can give reader some helps and hoped that the expert liberal with grants instruction simultaneously.

\section{Acknowledgements}

The authors would like to give their thanks to Jilin Social Science Foundation (NO.2014wy23) and Changchun Institute of Technology for their financial and technical support.

\section{References}

[1]. Josephine. Fish Paper of Plastic: A Fresh Look at Protective Packaging. Material Handling Management. 2010, 2, p34-35.

[2]. Mark Del Franco. Seven Tips for Better Picking and Packing. Catalog. Age 2003.

[3]. Zhou Sheng. Harm of Overdone Package of Goods and Relevant Solution. Shanxi Technology University. 2009, 8, 32-35.

[4]. Lai Shouliang. On the Motivation of Excessive packaging. Zhuzhou Teacher's College. 2005, 6, 45-48. 